\title{
Aprendendo a Usar Evidências nos Anos Iniciais do Ensino Fundamental ao Longo do Tempo: um Estudo da Construção Discursiva de Formas de Responder Questões em Aulas de Ciências
}

\section{Learning to Use Evidence in Elementary School Over Time: A Study of the Discursive Construction of Ways of Answering Questions in Science Lessons}

\section{Luiz Gustavo Franco ${ }^{(1)}$ Brasil \\ Danusa Munford ${ }^{(10}$ Brasil}

O uso evidências em aulas de ciências vem se consolidando como uma prática importante a ser desenvolvida desde o início do processo de escolarização. No presente estudo, investigamos como uma turma do $3^{\circ}$ ano do Ensino Fundamental construiu discursivamente a prática de uso de evidências. Baseamo-nos na perspectiva da etnografia em educação, utilizando ferramentas teórico-metodológicas da Microetnografia e Etnografia Interacional. Caracterizamos "modos de fazer" relacionados ao uso de evidências com base no uso de recursos discursivos: palavras/expressões que foram enfatizadas pelos participantes ao longo de interações face a face, através de pistas contextuais da fala, como alterações na entonação/volume e momentos de pausa. Indicamos como esses modos de fazer se transformaram ao longo do tempo e como os participantes negociaram um modelo compartilhado na construção de respostas usando evidências. Discutimos também implicações metodológicas para a pesquisa em argumentação na área Educação em Ciências e para prática pedagógica.

Palavras-chave: Uso de Evidências; Anos Iniciais do Ensino Fundamental; Etnografia em Educação, Argumentação, Ensino e aprendizagem de Ciências.

The use of evidence in science lessons has been considered an important practice to be developed in science education. In this study, we investigate how $3^{\text {rd }}$ graders constructed discursively the practice of using evidence. The theoretical and methodological framework of the study was grounded in Microethnography and Interactional Etnography. We characterize "ways of doing" related to evidence use based on the use of discursive resources: words/expressions that were emphasized by the participants in face-to-face interactions, through contextual cues of speech, such as intonation/volume shifts and pausing moments. We indicate how these ways of doing have changed over time and 
how participants negotiated a shared model in building answers using evidence. We also discuss methodological implications for research in Argumentation in science education and for classroom practice.

Keywords: Use of evidence; Elementary School Science; Ethnography in Education; Argumentation, Science Education.

\section{Introdução}

O presente artigo tem o objetivo de investigar como uma turma do $3^{\circ}$ ano do Ensino Fundamental construiu discursivamente a prática de uso de evidências em aulas de ciências. Este aspecto da argumentação tem se revelado um campo profícuo e de crescente interesse na área de Educação em Ciências (por exemplo, Manz \& Renga, 2017; Monteira \& Jiménez-Aleixandre, 2015; Osborne, Erduran \& Simon, 2004; Ryu \& Sandoval, 2012; Sasseron \& Carvalho, 2014; Yun \& Kim, 2015). O trabalho com evidências em sala de aula tem o potencial de auxiliar os alunos a construir um raciocínio mais próximo do pensamento científico (Jiménez-Aleixandre \& Erduran 2008; Kuhn, 1993) e as crianças têm contato com elementos de certas práticas através das quais a comunidade científica constrói conhecimento (Kelly, 2014).

Além disso, o uso de evidências também pode oferecer aos alunos uma visão alternativa sobre o que significa aprender ciências na escola. Como destacado por Sandoval e Milwood (2008), os estudantes, em geral, possuem uma visão tradicional de aprendizagem na qual os professores já sabem a "resposta correta" e o seu papel seria apenas dar essa resposta. $\mathrm{O}$ uso de evidências poderia, então, indicar outras possibilidades de construção de respostas e, consequentemente, outra relação com a aprendizagem das ciências. Nesse sentido, essa perspectiva tem o potencial de promover uma concepção de que não se deve aceitar ideias apenas porque elas parecem mais convincentes ou porque são defendidas por pessoas de maior poder. Portanto, outra contribuição da participação nessas práticas é a de acentuar o caráter de formação cidadã do ensino de ciências (Berland \& Reiser, 2011; Jiménez-Aleixandre \& Erduran, 2008).

Com o amplo desenvolvimento de pesquisas nessa temática nos últimos anos, principalmente através dos estudos relacionados à Argumentação no Ensino de Ciências, percebeu-se que não é uma tarefa simples trabalhar o uso de evidências no contexto da sala de aula. Autores têm relatado as dificuldades dos alunos em relacionarem afirmações e evidências apropriadas. Além disso, eles não demandam dados uns dos outros; nem tampouco refutarem as ideias dos colegas (Berland \& Reiser, 2009; Ryu \& Sandoval, 2012). Osborne, Erduran, e Simon (2004) citam outros desafios, como a tendência de estudantes: i) selecionarem evidências dando pouca atenção a dados que contradizem os resultados; ii) simplificarem de forma inadequada as evidências e chegarem a conclusões sem sustentação de dados suficientes; iii) usarem informações que vão além do apresentado para avaliar evidências; e iv) ignorarem certas informações na construção de respostas. 
Essas pesquisas sinalizam aspectos que podem auxiliar o professor durante o trabalho com evidências. Porém, buscamos tratar dessa questão sob outra perspectiva: ao invés de dar enfoque às dificuldades envolvidas nesse contexto e avaliar a capacidade dos alunos, consideramos que uma contribuição relevante é dar enfoque ao processo de aprendizagem dessa prática. Outros estudos recentes, voltados para investigação de práticas científicas nos Anos Iniciais, têm destacado que esse tipo de perspectiva constitui uma lacuna da área, uma vez que a maioria das pesquisas destaca se as crianças aprendem, ao invés de tentar compreender como elas aprendem (Jaber \& Hammer, 2016; Monteira \& Jiménez-Aleixandre, 2015).

Uma forma de dar maior visibilidade a esse processo é valorizar a proeminência da linguagem na construção do que acontece na sala de aula, como na presente pesquisa. Munford, Souto e Coutinho (2014) indicam que a abordagem etnográfica tem grandes potencialidades no contexto da educação científica, uma vez que tem como foco a perspectiva dos participantes situada em um espaço cultural e não apenas instrucional. Nesse sentido, tal abordagem pode auxiliar pesquisadores a desenvolver novas concepções do que significa ensinar e aprender ciências na escola para além do enfoque em construir orientações que podem ser aplicadas a diversos contextos, mas que frequentemente estão baseadas em noções de déficit ou relações processo-produto, ainda muito presentes (Kelly, 2005).

No presente estudo, exploramos a perspectiva etnográfica através de pressupostos e ferramentas da Análise Microetnográfica do Discurso e Etnografia Interacional (Bloome et al., 2008; Castanheira, Crawford, Dixon \& Green, 2001; Green, Dixon \& Zaharlic 2005). Esses referenciais oferecem elementos que nos permitem valorizar aspectos contextuais das interações. Esses aspectos são uma demanda dos estudos em Argumentação, uma vez que as ferramentas mais utilizadas possibilitam que apenas o conteúdo estrutural das interações sejam o foco das análises, enquanto as características do contexto de sua produção recebem pouca atenção (Yun \& Kim, 2015).

Analisamos o discurso de uma turma do $3^{\circ}$ ano do Ensino Fundamental em aulas de ciências. Nestes eventos, identificamos palavras/expressões que foram enfatizadas pelos participantes durante as interações e estavam relacionadas à construção da prática de uso de evidências. Desenvolvemos nossas análises em torno das seguintes questões:

Quais "modos de fazer" relacionados ao uso de evidências são mais significativos para uma turma de $3^{\circ}$ ano ao longo de uma sequência de aulas envolvendo argumentação?

\section{Como esses "modos de fazer" e seus significados se transformam ao longo do tempo?}

Como recursos discursivos relacionados a esses "modos de fazer" são usados pela turma para negociar um modelo compartilhado de como construir respostas para questões em aulas de ciências usando evidências? 


\section{Referenciais Teórico-metodológicos}

Este estudo se apoia em referenciais de diferentes campos, considerando a complexidade dos processos relacionados a aprender a usar evidências na argumentação em ciências. Quando falamos em uso de evidências em aulas de ciências, entendemos evidência como dado que sustenta uma conclusão ${ }^{1}$. Essa noção se baseia no modelo de Toulmin (2006), referencial bastante utilizado em pesquisas sobre Argumentação.

Contudo, para dar maior visibilidade ao processo argumentativo algumas alternativas metodológicas têm sido propostas, envolvendo a associação do Modelo de Toulmin a outras ferramentas de análise (por exemplo, Ferraz \& Sasseron, 2017; KnightBardsley \& Mcneill, 2016; Monteira \& Jiménez-Aleixandre, 2015; Sasseron \& Carvalho, 2008; Scarpa \& Trivelato, 2013) e o uso de outros referenciais de Argumentação (por exemplo, Franco \& Munford, 2016; Ibraim \& Justi, 2016; Martins, Ibraim \& Mendonça, 2016; Munford \& Teles, 2015).

No presente estudo, adotamos a concepção de evidência como proposta no Modelo de Toulmin associada a referenciais orientados pela perspectiva etnográfica (Bloome et al., 2008; Green et al., 2005). Como nosso interesse é compreender a construção da prática de uso de evidências durante a argumentação, esses referenciais se mostraram adequados por várias razões. Primeiramente, eles nos auxiliaram a desenvolver uma análise historicamente localizada, através do estabelecimento de relações entre parte (eventos específicos) e todo (a história da turma) (Green; et al., 2005). Ao descrever determinados eventos, fomos orientados por uma análise situada no tempo e no espaço (Bloome et al., 2013), o que possibilitou destacar transformações ao longo do tempo com base em continuidades e mudanças observadas nas práticas de uso de evidências. Isso proporcionou maior atenção ao processo da argumentação, ao invés do enfoque nos produtos argumentativos.

Além disso, tais referenciais foram importantes para dar visibilidade à perspectiva dos participantes, uma vez que nosso interesse era compreender o que foi mais significativo para o grupo ao construir a prática de uso de evidências. A Etnografia em Educação busca descrever "o que está acontecendo, o que significa, e o que é significativo para um grupo social a partir de uma perspectiva mais êmica (do nativo, insider) do que ética (externa, outsider)" (Bloome, 2012, p. 9, tradução nossa). Ou seja, busca valorizar o ponto de vista dos próprios membros. Na presente pesquisa, demos destaque a este aspecto através de características contextuais dos eventos com ênfase na forma do discurso (Gumperz, 1982), o que refletiu significados atribuídos pelo próprio grupo e

1 Entendemos que há diversas discussões sobre o que significa "evidência" no ensino de ciências. Por exemplo: distinções entre evidências genuínas e não-genuínas (Kuhn, 1993); distinção sobre a origem das evidências (dados primários ou secundários) (Hug \& McNeill, 2008); distinções entre o que é considerado dado e evidência (Sasseron \& Carvalho, 2014). Essas diferentes discussões têm implicações diretas sobre o trabalho com evidências em sala de aula e são fundamentais para o avanço na compreensão dessa prática em aulas de ciências. Porém, seguindo a perspectiva etnográfica de pesquisa, buscamos desenvolver as análises usando o mínimo de categorizações acerca do objeto de estudo e optamos por nos referir à evidência de forma mais ampla sem nos preocupar, a priori, com tipos de evidência ou em estabelecer distinções entre as evidências usadas pelos participantes nos eventos de análise. 
não significados atribuídos a priori pelos pesquisadores.

Nesse sentido, cabe destacar que, ao investigarmos o uso de evidências, o consideramos algo em processo de construção. Assim, em nossas análises, não consideramos, a priori, que os participantes já possuíam um modelo compartilhado do que seria usar evidências, mas que esses "modos de fazer" estavam sendo construídos ao longo do tempo. Os participantes construíam a prática de uso de evidências por meio de recursos semióticos através dos quais "suas histórias individuais e coletivas interagiam umas com as outras, com outras situações correlatas e pertinentes incluídas dentro dos ambientes materiais em que eles vivem" (Bloome, Carter, Christian, Otto, \& ShuartFaris, 2005, p. 6, tradução nossa).

Essas concepções colocam em destaque o foco que demos à análise de eventos, profundamente relacionado a pressupostos que nos orientaram. A partir de uma perspectiva holística (Green et al., 2005), construímos ferramentas macroscópicas de análise. Mais especificamente, construímos representações que permitiram a visualização e análise de eventos com maior ou menor grau de detalhamento e possibilitaram evidenciar as relações parte-todo consideradas na história do grupo (Green et al., 2005).

Baseados em pressupostos da Etnografia Interacional, vivenciamos a análise como um processo iterativo-responsivo (Castanheira et al., 2001): entramos no campo de pesquisa com uma questão mais abrangente e, em seguida, novas perguntas foram geradas, a partir do contato com o contexto estudado. Uma vez que novas questões foram desenvolvidas, buscamos analisar determinados eventos no nível microscópico (Green, et al., 2005). Portanto, a partir de uma visão mais geral derivada de análises macroscópicas, identificamos situações de maior interesse para pesquisa, ou seja, através dessa espécie de zoom sobre o conjunto de dados (Wolcott, 1994), foi possível identificar eventos específicos, gerar novas questões, novas formas de representação e de análise.

Ao oferecermos um enfoque na microanálise de eventos específicos, entendemos "evento" como um construto teórico-metodológico. O evento é uma heurística para produção de análises sobre o que as pessoas fazem em suas interações umas com as outras (Bloome et al., 2005) e os processos de seleção/análise de eventos são reflexo do modo como o pesquisador conduz suas investigações sobre determinada prática. ${ }^{2}$.

Na presente pesquisa, nos orientamos por uma lógica de investigação de eventos ainda pouco utilizada na área de Educação em Ciências, baseada nas análises de situações consideradas telling cases. Um telling case, ou caso expressivo ${ }^{3}$, é uma situação em que "circunstâncias particulares que envolvem um caso, tornam relações teóricas anteriormente obscuras, repentinamente, aparentes” (Mitchel, 1984, p. 239). No caso

2 Nesse sentido, seria possível descrever a prática de usar evidências em sala de aula a partir de diversas perspectivas de análise de eventos, por exemplo, comparando um conjunto de eventos antes e depois do desenvolvimento de uma sequência de aulas; mensurando o que se repete na prática dos membros do grupo em um conjunto de eventos; ou ainda, destacando o que acontece em eventos considerados "casos típicos".

3 Conforme proposto por Castanheira (2004), a expressão telling case pode ser traduzida como caso expressivo. No presente artigo, optamos por manter a expressão em língua inglesa pois a produção internacional com essa perspectiva é maior e, recentemente, têm ocorrido debates importantes em torno de seu uso (ver Andrews, 2016; Green \& Baker, 2017). 
da presente pesquisa, os telling cases foram situações em que certas características da turma, relacionadas ao uso de evidências, estavam mais visíveis no discurso oral e nos permitiram fazer inferências sobre a construção desta prática.

Telling cases são situações reveladoras relacionadas a "uma sequência de eventos a partir da qual o analista busca fazer inferências teóricas" (Mitchel, 1984, p. 238). Porém, não se deve pensar em telling case como um caso "típico", um evento isolado, ou representativo de algo que se repetia. A potencialidade do telling case reside na análise de momentos em que o fluxo cotidiano é rompido e certo aspecto da vida do grupo, até o momento oculto, fica evidente para o pesquisador e, possivelmente, para os próprios participantes (Agar, 1994).

Para fazer a análise dos telling cases, buscamos nos inspirar naquilo que Bloome et al. (2013) chamam de Análise Situada no Tempo e no Espaço, representado na Figura 1. Em nossas análises, nos apoiamos na apropriação da noção de cronotopo para a pesquisa em educação (veja Bloome et al., 2013). Consideramos os eventos como situações historicamente relacionadas em que as crianças estão construindo o uso de evidências como parte de um conjunto de processos que estão evoluindo e mudando.

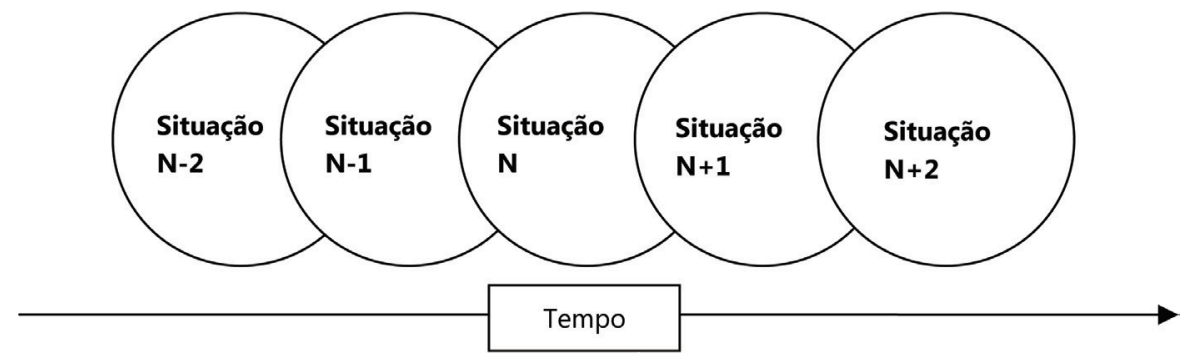

Figura 1. Representação da Análise Situada no Tempo e no Espaço (Bloome et al., 2013, p. 626)

Nossa intenção foi fazer uma análise integrada dos eventos. Como destacado pela conexão entre os eventos representados na Figura 1, buscamos reconstruir a história do grupo reconhecendo que, se as crianças usam evidências de certa forma em uma situação, isso está relacionado ao modo como essa prática foi construída em situações no passado e terá influência sobre a construção dessa prática em situações no futuro. Em outras palavras, os eventos do passado foram recurso para a construção dos eventos do presente que, por sua vez, servirão de recurso para os próximos eventos. Esse tipo de enfoque possibilita dar maior visibilidade ao processo de construção da argumentação.

Ainda com o objetivo de nos aproximarmos de uma perspectiva etnográfica de pesquisa, utilizamos alguns pressupostos e ferramentas da Microetnografia no processo de análise microscópica (Bloome et al., 2005, 2008). Esse referencial considera a centralidade do discurso enquanto representação do que o grupo constrói e, dessa forma, coloca em destaque as profundas relações entre linguagem e cultura. Nesse sentido, consideramos o uso de evidências como uma prática cultural em construção no grupo investigado.

Foi nas interações face a face dos eventos de análise que buscamos pistas para compreender como participantes constroem "modos de fazer" uso de evidências. 
Para buscar essas pistas, tentamos nos apropriar daquilo que Gumperz (1982) chama de contextualização. Contextualização diz respeito às formas com as quais as pessoas dão sentido às interações através de significados indexicais, uma vez que as pessoas usam pistas verbais, não verbais e comportamentais para se expressar (Gumperz, 1982). Entendemos que esses aspectos colocam em evidência outros elementos do discurso além do conteúdo estrutural e nos aproxima dos significados que os próprios participantes buscavam construir através da conversação. Usando essas informações contextuais, identificamos recursos discursivos que nos ajudaram a compreender a construção do uso de evidências pelo grupo.

\section{Contexto de Pesquisa}

Os dados apresentados no presente artigo se referem a um conjunto de aulas de ciências em uma turma dos Anos Iniciais do Ensino Fundamental de uma escola pública federal de uma grande cidade do Sudeste do Brasil. Essa turma foi acompanhada por nosso grupo de pesquisa ao longo de três anos, desde sua inserção no Ensino Fundamental. Apresentamos aqui análises do $1^{\circ}$ semestre de 2014 , quando a turma estava no $3^{\circ}$ ano.

Nesse período a turma contava com 27 alunos e as aulas acompanhadas foram conduzidas pela professora referência da turma, que lecionava Língua Portuguesa e Tópicos Integrados (História, Geografia e Ciências). As aulas de Ciências, representadas na Figura 2, foram conduzidas pela professora em parceria com membros do grupo de pesquisa. O esquema indica uma visão geral das temáticas trabalhadas ao longo dos três primeiros anos do Ensino Fundamental e um detalhamento do $1^{\circ}$ semestre de 2014 , no qual estão inseridas as situações analisadas no presente trabalho.

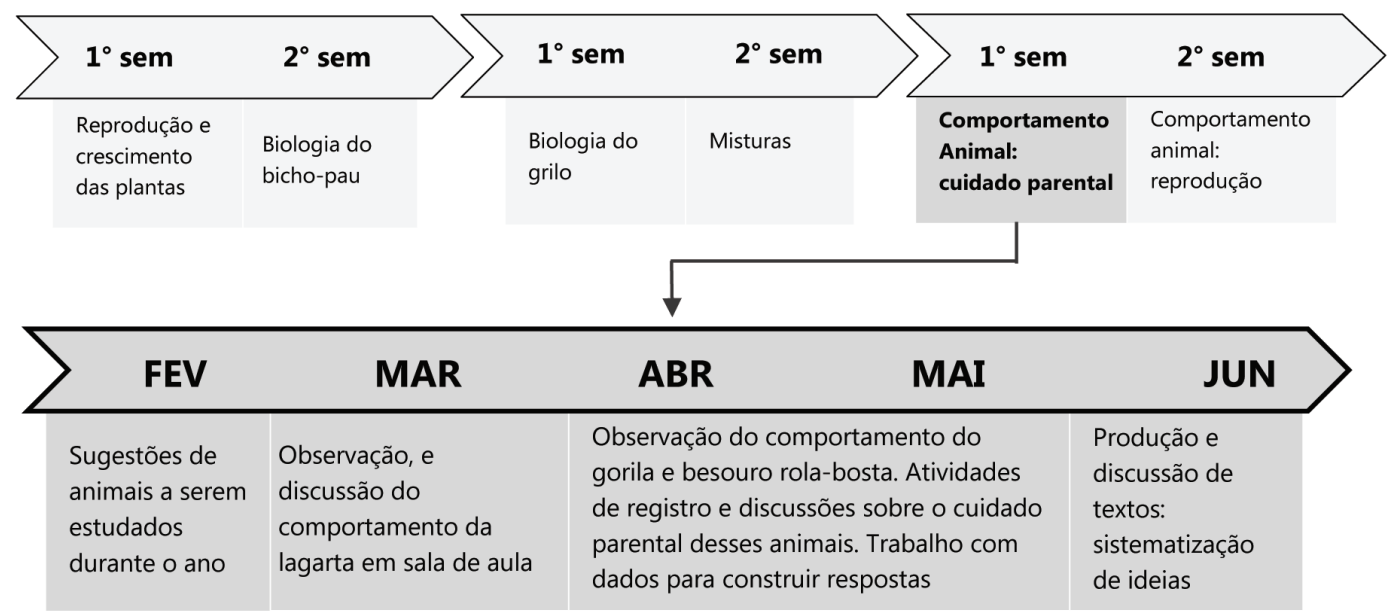

\begin{tabular}{l|l|l}
\multicolumn{1}{c|}{ Telling case 1} & \multicolumn{1}{c}{ Telling case $\mathbf{2}$} \\
Discussão sobre o & Discussão sobre o sexo do \\
comportamento da lagarta & besouro e do bicho-pau & $\begin{array}{l}\text { Telling case } \mathbf{3} \\
\text { Discussão sobre o } \\
\text { sexo do gorila }\end{array}$ \\
\hline
\end{tabular}

Figura 2. Sequência de aulas de ciências 
Essas aulas foram planejadas a partir de uma abordagem de ensino de ciências por investigação. Apesar da heterogeneidade de perspectivas sobre investigação, é possível identificar alguns aspectos considerados centrais por diversos autores (ver Munford \& Lima, 2007). Na presente pesquisa, as atividades estimularam as crianças a se engajar em atividades de problematização através de questões de cunho científico (Capecchi, 2013). Além disso, as crianças tinham de usar evidências para construir suas respostas e compartilhar suas conclusões (Carvalho, 2013; NRC, 2012; Zembaul-Saul, McNeill \& Hershberger, 2013).

O conceito científico desenvolvido ao longo das aulas durante o $1^{\circ}$ semestre de 2014 foi Adaptação Biológica. Como indicado pela Figura 2, esse conceito foi trabalhado através de atividades relacionadas ao comportamento de alguns animais, como lagarta, gorila e besouro rola-bosta.

\section{Fonte dos dados e processo de análise}

Os dados foram coletados através de observação participante (Spradley, 1980) com registro em caderno de campo e em vídeo (Green et al., 2005). Para o presente artigo, utilizamos dados referentes às aulas de ciências do $1^{\circ}$ semestre de 2014, o que representa um conjunto de 23 aulas.

Iniciamos o processo de análise macroscópica construindo um Quadro de Aulas com informações mais gerais sobre as aulas de ciências do $3^{\circ}$ ano. A partir das informações dessa representação, identificamos atividades que envolveram uso de evidências no $1^{\circ}$ semestre e decidimos analisar as aulas deste período.

Produzimos um novo quadro de descrições e selecionamos três aulas em que identificamos discussões orais em torno do uso de evidências. Em seguida, produzimos descrições mais detalhadas dessas aulas através da construção de Mapas de Eventos (Castanheira et al., 2001), o que nos possibilitou localizar situações consideradas telling cases (Mitchel, 1984).

O processo de análise microscópica que se seguiu envolveu a transcrição palavra-apalavra de três telling cases, utilizando-se unidades interacionais e unidades de mensagem. Unidades interacionais (UI) são blocos de conversação e constituem uma ferramenta para o estabelecimento de limites em eventos de análise (Bloome et al., 2008). No presente estudo, cada UI corresponde a um trecho de interações no qual o grupo organizava o discurso em torno de um determinado foco. Unidades de mensagem representam a menor unidade de significado na análise de uma conversação e sua produção está relacionada à necessidade dos membros de um grupo de construir limites compartilhados nas interações discursivas (Green \& Wallat, 1981). Estas fronteiras das falas foram estabelecidas a partir do uso de pistas de contextualização, como mudanças de entonação da fala, ritmo, ênfase, velocidade, pausa, postura, gestos, olhares, etc. (Gumperz, 1982). Esses sinais foram identificados por símbolos e as unidades organizadas em quadros de interações discursivas. Posteriormente, identificamos palavras/expressões que foram enfatizadas pelos participantes e estavam relacionadas à construção de práticas de uso de evidências. 


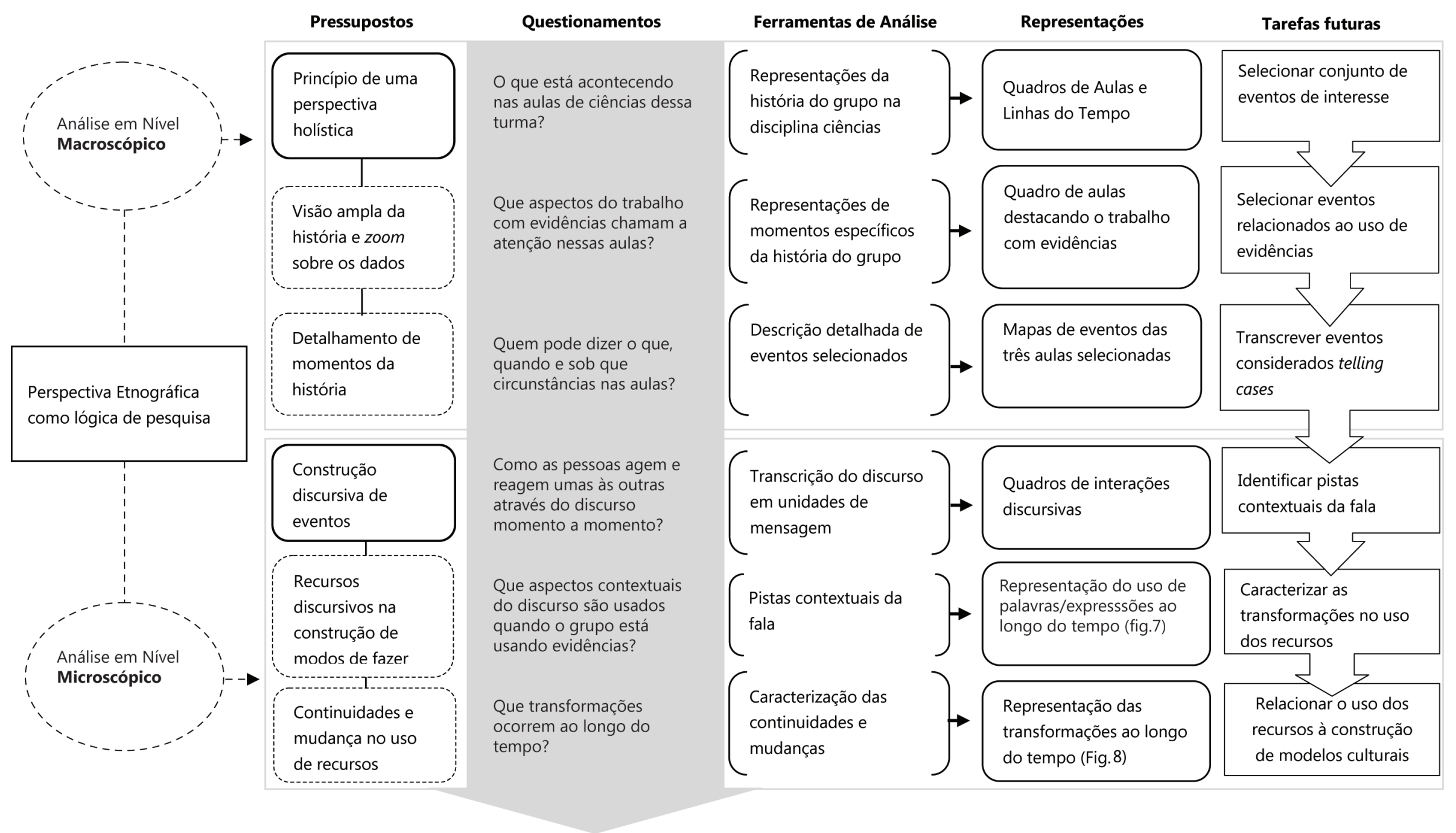

Figura 3. Representação dos procedimentos metodológicos da pesquisa 
Os procedimentos metodológicos que adotamos, bem como os pressupostos que nos orientaram na realização de tarefas ao longo da pesquisa são representados na Figura 3. Baseados em pressupostos da perspectiva etnográfica, nossos questionamentos foram se transformando ao longo do tempo, o que se refletiu no uso de diferentes ferramentas, formas de representação dos dados e tarefas.

\section{Resultados}

No relato de nossos resultados, apresentamos uma descrição geral dos três telling cases (TC), organizados em cinco unidades interacionais (UI) a partir dos diferentes focos em torno dos quais o grupo organizava suas discussões ${ }^{4}$. $\mathrm{O} \mathrm{TC} 1$ corresponde às unidades UI1, UI2, UI3 e os TC2 e TC3 às unidades UI4 e UI5, respectivamente.

Em seguida, abordamos as questões orientadoras da pesquisa. Partimos de exemplos das interações nos eventos para identificar "modos de fazer" relacionados ao uso de evidências considerados mais significativos para o grupo e para descrever transformações nesses "modos de fazer" ao longo do tempo (Questões 1 e 2). Finalmente, relacionamos os recursos discursivos utilizados nos eventos com um modelo de construção de respostas nas aulas de ciências compartilhado pelos participantes (Questão 3).

\section{Descrição geral dos eventos}

O telling case 1 (TC1), Discussão sobre o comportamento da lagarta, ocorreu na quarta aula de ciências no $3^{\circ}$ ano (Figura 2). No início da aula, a professora propôs a leitura de textos escritos produzidos individualmente pelas crianças na aula anterior, quando haviam observado o comportamento de uma lagarta que colegas encontraram na escola.

Durante a leitura dos registros, a professora ressaltou que, em algumas descrições, os alunos se referiam: i) a coisas que eles "viram", como "a lagarta está rodando" ou "a lagarta subiu e depois desceu"; e ii) a coisas que eles "achavam", como "eu acho que a lagarta não está bem" ou "eu acho que a lagarta está com fome". É no contexto destes acontecimentos que se insere o TC1. O evento se iniciou com uma discussão em torno da questão "Será que a lagarta estava bem?" (UI1). Posteriormente, a turma se voltou para a pergunta: "Será que a lagarta estava com fome?" (UI2) e discutiu a evidência do comportamento da lagarta de "ficar dando voltas sobre as folhas", sem chegar, contudo, a uma conclusão consensual. Em seguida, os alunos propuseram e discutiram possíveis formas de gerar dados para construir uma resposta à questão: "O que poderia ser feito para descobrir se a lagarta estava com fome?" (UI3).

O segundo telling case (TC2), Discussão sobre o sexo do besouro e do bicho-pau, ocorreu quatorze aulas de ciências depois do TC1 (Figura 2). A turma vinha estudando o comportamento de cuidado parental de dois animais: gorila e besouro rola-bosta ${ }^{5}$.

$4 T C$ foi usado para designar telling case, UI para designar unidade interacional, e $L$ para designar as linhas das transcrições nos quadros de interação.

5 Uma descrição mais detalhada dessa sequência de aulas se encontra disponível em Franco, Cappelle, Munford \& França (2014). 
Nesta aula, a proposta era trabalhar com um texto escrito que trazia informações sobre cuidado parental. Porém, antes do início da leitura, alguns alunos trouxeram para a sala um besouro que encontraram durante o recreio e o aluno Vinícius questionou: "Como saber se esse besouro é macho ou fêmea?". Alguns colegas responderam que bastava observar o besouro por baixo para saber. Contudo, a professora se lembrou de um evento que ocorreu em 2012, quando a turma discutiu como descobrir qual era o sexo de um bicho-pau. A partir daí, os alunos se engajaram em uma narrativa coletiva sobre como o grupo construíra respostas nesse outro momento de sua história.

O terceiro telling case (TC3), Discussão sobre o sexo do gorila, ocorreu quatro aulas de ciências depois do TC2, em junho do $3^{\circ}$ ano (Figura 2). A turma estava concluindo seus estudos sobre cuidado parental. $\mathrm{Na}$ aula anterior, a professora havia pedido que os alunos produzissem um texto relatando o que aprenderam de ciências durante o semestre, e, em seguida, algumas crianças leram suas produções para os colegas e discutiram os relatos.

Em seu texto, a aluna Nara fez a pergunta: "Por que o pai do gorila não estava no vídeo?” Ela recordava de uma das primeiras aulas de ciências do ano, em abril, quando a turma assistiu a um vídeo que mostrava um gorila adulto cuidado de um gorila filhote e ficou intrigada com a presença de apenas um gorila adulto, supostamente a mãe. Os colegas começaram a discutir a questão e novas perguntas foram geradas. A aluna Nina, por exemplo, disse que antes de responder à questão de Nara, era preciso saber se o gorila do vídeo era o pai ou a mãe. Nesse contexto se insere o TC3, que envolve a discussão sobre o sexo do gorila visto no vídeo. Os alunos assistiram novamente ao vídeo e tentaram identificar evidências que ajudassem a responder a questão de Nina.

\section{Que "modos de fazer" são mais significativos no uso de evidências ao longo de uma sequência de aulas envolvendo argumentação? Como esses "modos de fazer" se transformam ao longo do tempo?}

Identificamos certas palavras/expressões enfatizadas pelos participantes do grupo nas interações que pareciam ter relações com o uso de evidências. As palavras/ expressões identificadas foram: saber, achar que, ter certeza, olhar, ver e observar.

O uso destes recursos discursivos é compreendido como ações significativas na construção de "modos de fazer" uso de evidências. Porém, ao discutirmos o uso de "saber" ou "observar", por exemplo, não estamos nos referindo apenas às ações imediatas/específicas de saber e observar per se. A análise situada no tempo e no espaço deu destaque aos processos de negociação sobre o que é "saber" ou o que é "observar" para os participantes e as transformações nestas ações e em como elas se articulam para constituir o que chamamos de "modos de fazer".

Nesta seção, abordamos inicialmente as relações entre saber, ter certeza e achar que, dada a relação dicotômica que o grupo atribuiu a essas palavras/expressões. Em um segundo momento, nos voltamos para o uso das palavras ver, olhar e observar, que foram utilizadas pelo grupo de modo semelhante. 
Ao longo das unidades, saber, ter certeza e achar que foram usadas de formas diferentes. $\mathrm{Na}$ UI2, a professora enfatizou as palavras/expressões achar que (L4) e saber (L9), quando o grupo discutia a questão sobre a fome da lagarta (Figura $4^{6}$ ).

\begin{tabular}{|c|c|c|}
\hline \multicolumn{3}{|c|}{ Unidade Interacional 2} \\
\hline Linha & Falante & Discurso \\
\hline 1 & \multirow{10}{*}{ Professora } & $\underline{\mathrm{Oh} I}$ \\
\hline 2 & & Agora eu vou perguntar uma que eu fiquei com dúvida I \\
\hline 3 & & Teve gente que colocou assim I \\
\hline 4 & & Eu acho I \\
\hline 5 & & que essa lagar- \\
\hline 6 & & Lagarta I \\
\hline 7 & & está com fome I \\
\hline 8 & & Tem jeito I \\
\hline 9 & & De saber I \\
\hline 10 & & Se ela estava com fome $\uparrow$ \\
\hline 11 & $\begin{array}{l}\text { Nara e } \\
\text { outros }\end{array}$ & $\begin{array}{l}\text { Tem I Nara está em pé ao lado da professora e levanta a mão direita. A } \\
\text { professora também levanta o braço }\end{array}$ \\
\hline 12 & Professora & Agora senta que eu quero ouvir outras pessoas I diz para Nara \\
\hline 13 & Vinícius & Levanta a mão direita pedindo para ser escolhido para falar \\
\hline 14 & \multirow{5}{*}{ Professora } & Eu quero ouvir umas meninas que não estão participando I \\
\hline 15 & & Tina e Lívia I \\
\hline 16 & & Tem jeito de saber I \\
\hline 17 & & $\begin{array}{l}\text { com certeza I enquanto diz 'com certeza', a mão esquerda sobe até a testa e } \\
\text { desce em seguida. Dedo indicador está unido ao polegar. }\end{array}$ \\
\hline 18 & & $\begin{array}{l}\text { se essa lagarta estava com fome I mão esquerda sobe e desce duas vezes } \\
\text { seguidas. Dedo indicador está unido ao polegar. }\end{array}$ \\
\hline
\end{tabular}

Figura 4. Interações discursivas de um trecho da Unidade Interacional 2

Fonte: elaboração dos autores

Entre as linhas 4 e 7, a professora afirmou: "Eu acho que essa lagarta está com fome". A professora deu ênfase ao verbo achar, sinalizada pela pausa após essa palavra antes de completar a frase. Através dessa afirmação, a professora trouxe a memória de alguns registros de alunos sobre o comportamento da lagarta.

Dessa forma, houve um movimento de dar destaque a diferenças entre achar e saber. Antes, alguns alunos achavam alguma coisa, a partir de agora, a participação na discussão demandou pensar em alguma forma de saber a resposta: saber e achar apareceram com usos distintos e assumiram uma relação dicotômica nesse contexto da discussão.

\footnotetext{
6 Significados dos símbolos: $\uparrow \downarrow$ (aumento/diminuição da entonação); XXXX (fala indecifrável); ênfase; (maior e menor volume); mạiọ.velọcidạde; ${ }^{\mathrm{L}} \Gamma$ (sobreposição de falas); vogal+ (vogal alongada); Comportamento não verbal em itálico; I (pausa); IIII (pausa longa); - (palavra incompleta).
} 
A palavra enfatizada - saber - foi encontrada, antes e depois da UI2. Na UI1, a professora, Nara e Júlio já haviam usado achar e saber (Figura 5). A professora iniciou a discussão usando a palavra achar ao perguntar se Nara achava que a lagarta não estava bem (L2). Ao responder, Nara afirmou: "Porque eu acho que ela queria um espaço maior" (L5). Neste contexto, a professora questionou Júlio: "Eu posso ter certeza disso?", enfatizando a palavra certeza, através da entonação e da separação silábica da palavra. Júlio afirmou que não era possível ter certeza se a lagarta estava bem (L13) porque Nara não sabia (L15).

Assim, saber foi usada por Júlio para expressar que não bastava achar que a lagarta estava bem (ou não), seria preciso saber. Se a aluna (Nara) não sabia, não tinha como responder com certeza.

\begin{tabular}{|c|c|c|}
\hline \multicolumn{3}{|c|}{ Unidade Interacional 1} \\
\hline Linha & Falante & Discurso \\
\hline 1 & \multirow{2}{*}{ Professora } & Quando você olhou aquela mesa I \\
\hline 2 & & Você achou que a lagarta não estava bem ali $\uparrow$ \\
\hline 3 & Nara & Não I $\mathbf{\nabla}$ \\
\hline 4 & Professora & Por quê $\uparrow$ \\
\hline 5 & \multirow{3}{*}{ Nara } & Por causa que eu acho que ela queria um espaço maio $+r \boldsymbol{\nabla}$ \\
\hline 6 & & Para ela ficar fazendo suas tarefas $\mid \mathbf{\nabla}$ \\
\hline 7 & & e a mesa não é muito grande I $\nabla$ \\
\hline 8 & \multirow{4}{*}{ Professora } & Eu po- \\
\hline 9 & & \multirow{2}{*}{$\begin{array}{l}\text { Júlio I } \\
\text { Eu posso ter ce+rteza disso } \uparrow \text { Enquanto diz a palavra certeza, o dedo } \\
\text { indicador acompanha a divisão silábica da palavra. }\end{array}$} \\
\hline 10 & & \\
\hline 11 & & \multirow{2}{*}{$\begin{array}{ll}\text { Que ela não estava gostando daquele lugar } \uparrow & \mathrm{L} \\
\text { Não } & \Gamma \\
\end{array}$} \\
\hline 12 & Aluno & \\
\hline 13 & Júlio & Não I $\mathbf{\nabla}$ \\
\hline 14 & Professora & Por quê $\uparrow$ \\
\hline 15 & Júlio & Porque se ela não sabe I $\mathbf{\nabla}$ \\
\hline 16 & \multirow{3}{*}{ Professora } & Não sabe I \\
\hline 17 & & Mas a gente estava olhando I \\
\hline 18 & & Não estava $\uparrow$ \\
\hline 19 & Breno & Estava I \\
\hline 20 & Professora & Como é que a gente vai saber se ela estava gostando ou não $\uparrow$ \\
\hline 21 & Breno e Júlio & Levantam os ombros sinalizando que não sabem como responder \\
\hline 22 & \multirow{2}{*}{ Breno } & Se ela tiver I \\
\hline 23 & & Se ela tivesse $\mathrm{a}^{+}$ \\
\hline 24 & Ramon & Eu sei I levanta a mão \\
\hline
\end{tabular}

Figura 5. Interações discursivas da Unidade Interacional 1 (continua) 


\begin{tabular}{|c|c|c|}
\hline \multicolumn{3}{|c|}{ Unidade Interacional 1} \\
\hline Linha & Falante & Discurso \\
\hline 25 & Breno & Aquela máquina que eu vi no desenho I coloca as mãos sobre a cabeça \\
\hline 26 & Aluno & $\mathrm{XXXX}$ \\
\hline 27 & \multirow{3}{*}{ Breno } & Não I \\
\hline 28 & & Uma máquina que eu vi no desenho no cartoon que passava o+ \\
\hline 29 & & $\begin{array}{l}\text { o cérebro de um para o cérebro de outro I começa com as mãos na cabeça e faz } \\
\text { um movimento com as duas mãos para o lado esquerdo }\end{array}$ \\
\hline 30 & \multirow{3}{*}{ Professora } & $\underline{\mathrm{Ah}}+\mathrm{I}$ \\
\hline 31 & & Então aquele ali é o que eu preciso saber isso $\uparrow$ \\
\hline 32 & & Tem alguma coisa dentro do cérebro Breno $\uparrow$ \\
\hline 33 & Alunos & XXXX \\
\hline 34 & \multirow{5}{*}{ Professora } & Breno I \\
\hline 35 & & Eu precis- coloca a mão esquerda próximo às carteiras em sua frente \\
\hline 36 & & $\begin{array}{l}\text { Para saber isso eu tenho que saber alguma coisa que está acontecendo dentro } \\
\text { do cérebro } \uparrow \text { durante a fala, a mão esquerda mostra a cabeça }\end{array}$ \\
\hline 37 & & Agora eu vou perguntar I \\
\hline 38 & & Eu tenho certeza que ela rodou $\uparrow$ \\
\hline 39 & Breno & Tem I \\
\hline 40 & Professora & Como $\uparrow$ \\
\hline 41 & Breno & Você viu I \\
\hline 42 & \multirow{2}{*}{ Professora } & Porque a gente I \\
\hline 43 & & $\underline{\mathrm{Vi}+\mathrm{u} I}$ \\
\hline
\end{tabular}

Figura 5. Interações discursivas da Unidade Interacional 1

Fonte: elaboração dos autores

Posteriormente, já na UI4, saber volta a aparecer na fala de Vinícius em dois momentos, enquanto a turma discutia sobre o sexo do besouro trazido para sala de aula (Figura 6).

\begin{tabular}{|c|l|l|}
\hline \multicolumn{3}{|l|}{ Unidade Interacional 4} \\
\hline Linha & Falante & Discurso \\
\hline 1 & \multirow{4}{*}{ Vinícius } & Professora I \\
& & Mas será que tem como a gente saber I \\
& & se é fêmea ou se é macho $\uparrow$ \\
\hline 3 & Ricardo & Te $+\mathrm{m}$ I \\
\hline 5 & \multirow{2}{*}{ Paulo } & $\begin{array}{l}\text { É só virar de cabeça para baixo I Faz movimento com as mãos como se virasse } \\
\text { algum objeto e observasse }\end{array}$ \\
\hline 6 & \multirow{2}{*}{ Ricardo } & É I \\
\cline { 3 - 4 } & E ver se tem o+ \\
\hline 7 & &
\end{tabular}

Figura 6. Interações discursivas de um trecho da Unidade Interacional 4 (continua) 


\begin{tabular}{|c|c|c|}
\hline \multicolumn{3}{|c|}{ Unidade Interacional 4} \\
\hline Linha & Falante & Discurso \\
\hline 8 & \multirow{2}{*}{ Professora } & $\begin{array}{l}\text { Depois tem que tomar uma decisão de onde vai colocar I Professora ainda } \\
\text { está se referindo à caixa com o besouro }\end{array}$ \\
\hline 9 & & porque eu estou viajando hoje I \\
\hline 10 & \multirow{2}{*}{ Vinícius } & É mas a gente também que saber I \\
\hline 11 & & Se é macho ou se é fêmea I \\
\hline 12 & \multirow{2}{*}{ Mariana } & Karina I \\
\hline 13 & & Para onde $\uparrow$ Professora faz um sinal pedindo que a aluna aguarde \\
\hline 14 & \multirow{5}{*}{ Professora } & Olha aqui I \\
\hline 15 & & O Vinícius está fazendo uma pergunta I \\
\hline 16 & & que eu já estou ficando curiosa I \\
\hline 17 & & Como sabe+r I \\
\hline 18 & & Psi+u I \\
\hline 19 & \multirow{4}{*}{ Ricardo } & Eu sei I $\mathbf{\Delta}$ levanta a mão direita \\
\hline 20 & & É fácil professora I levanta da cadeira \\
\hline 21 & & $\mathrm{E}+\mathrm{I}$ \\
\hline 22 & & É só virar de cabeça para baixo e+ I \\
\hline 23 & Vinícius & E se a patinha tiver $\mathrm{XXXX}$ \\
\hline 24 & Ricardo & É só pegar uma lupa faz gesto de observação com a lupa \\
\hline 25 & \multirow{5}{*}{ Professora } & Olha bem gente I \\
\hline 26 & & Primeira coisa I \\
\hline 27 & & $\mathrm{Co}+$ mo saber I \\
\hline 28 & & Olha a pergunta do Ricardo I \\
\hline 29 & & Do Ricardo ou do Vinícius $\uparrow$ \\
\hline 30 & Estagiária & Vinícius I Vinícius levanta a mão \\
\hline 31 & \multirow{2}{*}{ Professora } & Como saber I \\
\hline 32 & & se esse besouro é macho ou fêmea $\uparrow$ \\
\hline 33 & Gláucio & Olhando por baixo I \\
\hline 34 & Ricardo & \multirow{2}{*}{$\begin{array}{l}\text { É } \\
\text { Ah mas XXXX }\end{array}$} \\
\hline 35 & Vinícius & \\
\hline 36 & Professora & Mas vai ver o que lá embaixo $\uparrow$ \\
\hline 37 & \multirow{3}{*}{ Ricardo } & É fácil é fácil I levanta a mão direita e se levanta da cadeira \\
\hline 38 & & $\begin{array}{l}\text { Pega a lupa e aí se tiver um pintinho I Ricardo faz gesto de observação com } \\
\text { a lupa. Vinícius discorda fazendo sinal negativo com a cabeça. }\end{array}$ \\
\hline 39 & & $\begin{array}{l}\text { Ou um negocinho assim I faz movimento com o dedo indicador da mão } \\
\text { direita para frente }\end{array}$ \\
\hline 40 & \multirow{2}{*}{ Professora } & Uai mas I \\
\hline 41 & & bicho-pau nós vimos pintinho nele $\uparrow$ \\
\hline
\end{tabular}

Figura 6. Interações discursivas de um trecho da Unidade Interacional 4 (continua) 


\begin{tabular}{|c|l|l|}
\hline \multicolumn{2}{|l|}{ Unidade Interacional 4} \\
\hline Linha & Falante & Discurso \\
\hline 42 & \multirow{4}{*}{ Vinícius } & Não I \\
& & A gente viu porque a gente ficou sabendo I \\
& & A gente teve uma pista I \\
& & que o maior era a fê+mea I \\
\hline 44 & &
\end{tabular}

Figura 6. Interações discursivas de um trecho da Unidade Interacional 4

Fonte: elaboração dos autores

Nessa interação, o questionamento inicial de Vinícius (L2) se enquadrou em uma dúvida de cunho mais metodológico. O verbo saber estava inserido em uma discussão que se direcionou no sentido de como construir a resposta e não no sentido de gerar uma resposta direta sobre o sexo do besouro. Saber, nesse caso, era ter acesso a alguma informação que sustentaria uma conclusão. A professora havia questionado se um dado sugerido pelos alunos (presença de pintinho) havia sido observado em uma situação semelhante ocorrida no passado, há quase dois anos, quando estudaram o bicho-pau. Em resposta, Vinícius afirmou: "Não! A gente viu porque a gente ficou sabendo, a gente teve uma pista" (L42-44). Saber, neste caso, estava relacionado ao mesmo contexto da conversa anterior: ter acesso a um dado (tamanho do animal), que permitia fazer certa afirmação. Nesse caso, tratava-se de afirmar se o bicho-pau era fêmea ou era macho.

Outras palavras destacadas ao longo das interações estavam relacionadas mais diretamente à observação: olhar, ver, observar. Nas linhas 17 e 18 da unidade 1 (ver Figura 5), a professora questionou a colocação de Júlio: "Mas a gente estava olhando, não estava?" No contexto da discussão entre achar que-saber-ter certeza que ocorria nesse momento, a professora introduziu o verbo olhar. Desde a UI1, a observação apareceu nas colocações dos instrutores e dos alunos, ora através do verbo olhar, ora do verbo observar, mas principalmente, através do verbo ver.

Olhar apareceu em outro momento na unidade 1 (ver Figura 5): quando a professora questionou Nara na linha 1 (Quando você olhou aquela mesa) e uma ênfase na entonação foi dada ao verbo ver nesta mesma unidade na interação entre a professora e Breno. Depois que Breno fez uma sugestão de realizar a troca de cérebros com a lagarta para descobrir se ela estava bem ou não, a professora questionou na linha 38: "Eu tenho certeza que ela rodou?". Novamente, a ênfase na palavra certeza. Breno diz que sim e a professora o questionou perguntando o porquê. Breno respondeu: "Você viu!" (L41). O aluno enfatizou o verbo ver e a professora repetiu: "Porque a gente viu!" (L42-43). Na afirmação da professora, a palavra viu teve a entonação enfatizada e a vogal ' $i$ ' alongada.

Nessa interação, pistas contextuais destacam a dicotomia que estava sendo construída entre achar e saber: a ênfase em certeza e viu dada pela professora e a entonação que Bruno empregou ao usar o verbo ver. Ver estava sendo associado à certeza de uma resposta, em contraposição a apenas achar. Destacamos que o uso desse verbo ocorreu desde a primeira interação e foi retomado ao longo dos eventos. Na unidade interacional 
3, a pesquisadora propôs que o grupo pensasse em situações capazes de gerar evidências para sustentar uma resposta (Figura 7).

No fluxo da interação em que o verbo ver estava sendo associado a ter certeza de uma afirmação na UI1 (ver Figura 7), a pesquisadora usou esta palavra na UI3 (ver Figura 7, a seguir) do mesmo telling case. A pesquisadora questionou "o quê que a gente pode fazer para ver se ela tá com fome mesmo?" (L1-2). Ver, neste caso, apesar de ainda estar próximo do sentido de ter certeza, apareceu como uma transição para o sentido de ter acesso a um dado observável, uma vez que a questão engajou os alunos em fazer algo que auxiliasse o grupo na construção da resposta e não, meramente, ver a resposta. Este mesmo uso voltou a aparecer na intervenção da pesquisadora na linha 68 .

\begin{tabular}{|c|c|c|}
\hline \multicolumn{3}{|c|}{ Unidade Interacional 3} \\
\hline Linha & Falante & Discurso \\
\hline 1 & \multirow{4}{*}{ Pesquisadora } & Quê que a gente pode fazer I \\
\hline 2 & & $\begin{array}{l}\text { para ver se ela está com fome mesmo } \uparrow \text { Vinícius permanece com a mão } \\
\text { direita levantada }\end{array}$ \\
\hline 3 & & Alguém tem alguma ideia $\uparrow$ Vinícius permanece com a mão direita levantada \\
\hline 4 & & O Vinícius quer falar $\uparrow$ \\
\hline \multicolumn{3}{|c|}{ [5-28] Discussões com outros alunos } \\
\hline 29 & \multirow{6}{*}{ Vinícius } & A gente pode pegar é+ I \\
\hline 30 & & Vários tipos de+ I \\
\hline 31 & & Folha e por lá I \\
\hline 32 & & se ela não comer I \\
\hline 33 & & se ela não comer uma aí tem a outra I \\
\hline 34 & & e se ela não comer nenhuma aí a gente não sabe o quê que ela come I \\
\hline 35 & Pesquisadora & Isso é uma ideia legal I \\
\hline 36 & Maurício & A gente pode saber I \\
\hline 37 & Vinícius & A gente também pode por folha perto dela para ver se ela come I \\
\hline \multicolumn{3}{|c|}{ [38-66] Discussões relacionadas à proposta de Vinícius } \\
\hline 67. & \multirow{9}{*}{ Pesquisadora } & O quê que a gente podia fazer I voltada para o aluno Ramon \\
\hline 68. & & Para ver I \\
\hline 69. & & Se ela estava com fome ou não I \\
\hline 70. & & Teve uma sugestão I \\
\hline 71. & & era matar ela que a gente já descartou de fazer I \\
\hline 72. & & E o Ra- \\
\hline 73. & & Vinícius e o Ricardo tão falando para gente a ideia de dar várias folhas I \\
\hline 74. & & alimentos diferentes para ela para ver se ela ia comer alguma coisa I \\
\hline 75. & & a gente teria uma boa evidência I \\
\hline 76. & Maurício & XXXX Ramon com a mão levantada \\
\hline
\end{tabular}

Figura 7. Interações discursivas de um trecho da Unidade Interacional 3 (continua) 


\begin{tabular}{|c|l|l|}
\hline \multicolumn{3}{|l|}{ Unidade Interacional 3} \\
\hline Linha & Falante & Discurso \\
\hline 77. & Pesquisadora & Maurício tem o Ramon para terminar I \\
\hline 78. & Professora & E o Perseu I \\
\hline 79. & Pesquisadora & E a Camila I \\
\hline 80. & & Dá para ver a lagarta I \\
81. & Ramon & $\begin{array}{l}\text { então se a barriguinha dela estiver mexendo em ondas é porque ela está com } \\
\text { fome I }\end{array}$ \\
\hline
\end{tabular}

Figura 7. Interações discursivas de um trecho da Unidade Interacional $3^{7}$

Fonte: elaboração dos autores

Os alunos Vinícius e Ramon, que ofereceram propostas em resposta à questão da pesquisadora, também usaram o verbo ver ao longo dessa interação, passando a usálo no sentido de levantamento e interpretação de evidências. Ou seja, ver deixou de ter sentido de ter certeza e passou a ter sentido de observar. A proposta de Vinícius foi oferecer diferentes tipos de folha à lagarta e, em suas palavras, seria possível ver se ela come (L37). Dessa forma, a consequência de sua proposta possibilitaria ver algo que seria usado para dar a resposta - não mais "ver a resposta”. Ramon, por sua vez, usou o verbo ver na introdução de sua proposta: "dá para ver a lagarta, então, se a barriguinha dela estiver mexendo em ondas, é porque ela está com fome” (L80-81). Para ele, a possibilidade de ver a lagarta era a prerrogativa da proposta. Como era possível ver, seria possível ter um sinal para saber se ela estava com fome. Vinícius e Ramon se apropriaram do mesmo uso de ver: observar um dado capaz de sustentar uma conclusão.

Na UI 4 (ver Figura 6), o verbo ver apareceu nas colocações de Ricardo e da professora. Vinícius questionou se haveria como "saber" se o besouro que foi encontrado na escola era macho ou fêmea. Paulo afirmou que teria que virar de cabeça para baixo e Ricardo, disse: “E ver se tem o...” (L7). Para eles, seria preciso ver alguma característica anatômica do besouro para dar a resposta. Usando ver de forma similar, Glauco afirmou que deveria olhar por baixo (L33), e a professora questionou: "Mas vai ver o que lá embaixo?" (L36). O verbo ver foi usado para demandar diretamente uma evidência. Ao ouvir a resposta de Ricardo, que sugeriu que eles veriam o pintinho do besouro, a professora perguntou: "Uai, mas bicho-pau nós vimos pintinho nele?" (L40-41). Neste caso, ver foi relacionado não apenas a observar para obter evidências para construir uma resposta, mas também à experiência em um evento passado de ter acesso a um dado que auxiliou o grupo na construção de uma resposta para questão semelhante em outro momento de sua história.

Na unidade UI5, os participantes usaram ver e observar em um contexto similar das ações nas UI3 e UI4. A turma assistiu novamente a um vídeo exibido no início do

7 A unidade interacional 3 é muito longa. Devido a questões de espaço, consideramos pertinente apresentar apenas alguns trechos da mesma. Os trechos apresentados contêm as interações em que as palavras/expressões discutidas em nossa pesquisa apareceram. 
ano para tentar saber se o gorila presente no vídeo era o pai ou a mãe (Figura 8).

Logo após o início da exibição do vídeo, Glauco destacou: “Tem que observar o grandão" (L13). O aluno sinalizou que o grupo deveria estar atento para ver alguma coisa no gorila grande que ajudasse a responder a questão em discussão. A professora retomou essa colocação diversas vezes destacando, com ênfase, que a atividade demandava observação (L17-19-22-27). Nestes casos, de modo similar ao que ocorreu no passado, observar estava inserido no contexto de usar um dado para sustentar uma conclusão.

Em suma, modos de fazer foram discursivamente construídos pelo grupo a partir do uso dessas palavras/expressões ao longo do tempo. As diferentes formas como palavras/expressões foram usadas ao longo das interações indicaram como a linguagem sustentou um processo de mudança no modo como as crianças construíram a prática de uso de evidências em sala de aula.

Saber, por exemplo, foi inicialmente associado a ter certeza de algo, em contraposição a achar em uma discussão relacionada ao estabelecimento de distinções: "saber alguma coisa" era diferente de "achar". Posteriormente, saber passou a ser usado como referência ao acesso a dados que seriam capazes de sustentar conclusões. De modo semelhante, ver, inicialmente, havia sido associado a ter certeza de algo. Ao longo das interações, observou-se uma mudança. Palavras relacionados à observação, como os verbos ver, olhar e observar passaram a ser usados para indicar observação de dados que poderiam auxiliar o grupo na construção de respostas.

\begin{tabular}{|c|c|c|}
\hline \multicolumn{3}{|c|}{ Unidade Interacional 5} \\
\hline Linha & Falante & Discurso \\
\hline 1 & \multirow{2}{*}{ Professora } & O gorila grande I \\
\hline 2 & & É o que $\uparrow$ \\
\hline 3 & Guilherme & Se ele é o macho ou fêmea I \\
\hline 4 & \multirow{3}{*}{ Professora } & Se ele é o pai ou a mãe I \\
\hline 5 & & o que significa macho ou fêmea I \\
\hline 6 & & Pode ir I \\
\hline 7 & Alunos & XXXX falam ao mesmo tempo \\
\hline 8 & \multirow{4}{*}{ Professora } & $\mathrm{Psi}++\mathrm{ul}$ \\
\hline 9 & & Nara I \\
\hline 10 & & Ô Jonas como é que você vê o filme de costas $\uparrow$ \\
\hline 11 & & IIII pausa para exibição do vídeo \\
\hline 12 & Alunos & XXXX alguns fazem comentários durante a exibição \\
\hline 13 & Glauco & Tem que observar o grandão I \\
\hline 14 & Professora & Psi++u I \\
\hline 15 & Aluno & É mulher I \\
\hline 16 & \multirow{2}{*}{ Professora } & Ricardo I \\
\hline 17 & & Observar I \\
\hline
\end{tabular}

Figura 8. Interações discursivas de um trecho da Unidade Interacional 5 (continua) 


\begin{tabular}{|c|l|l|}
\hline \multicolumn{3}{|l|}{ Unidade Interacional 5} \\
\hline Linha & Falante & Discurso \\
\hline 18 & Aluno & É a mãe I \\
\hline 19 & Professora & Observar I \\
\hline 20 & Mariana & Dá para ver uma mulher ali I \\
\hline 18 & Aluno & É a mãe I \\
\hline 19 & Professora & Observar I \\
\hline 20 & Mariana & Dá para ver uma mulher ali I \\
\hline 21 & \multirow{2}{*}{ Professora } & Psiu I \\
22 & & Observar I \\
\hline 23 & \multirow{2}{*}{ Mariana } & Eu vi uma mulher ali atrás tinha uma calça I fala para o pesquisador \\
24 & & Psiu IIII \\
\hline 25 & Ricardo & Isso daí é homem I \\
\hline 26 & \multirow{2}{*}{ Professora } & Ricardo I \\
& & Observar IIII \\
\hline 27 & &
\end{tabular}

Figura 8. Interações discursivas de um trecho da Unidade Interacional 5

Fonte: elaboração dos autores

Dessa forma, esses modos de fazer, na perspectiva do grupo, passaram a se aproximar do que, classicamente, é entendido na área de Educação em Ciências como usar um dado para sustentar uma conclusão, aspecto relevante no que diz respeito ao uso de evidências em sala de aula. Esse processo está representado na Figura 9:

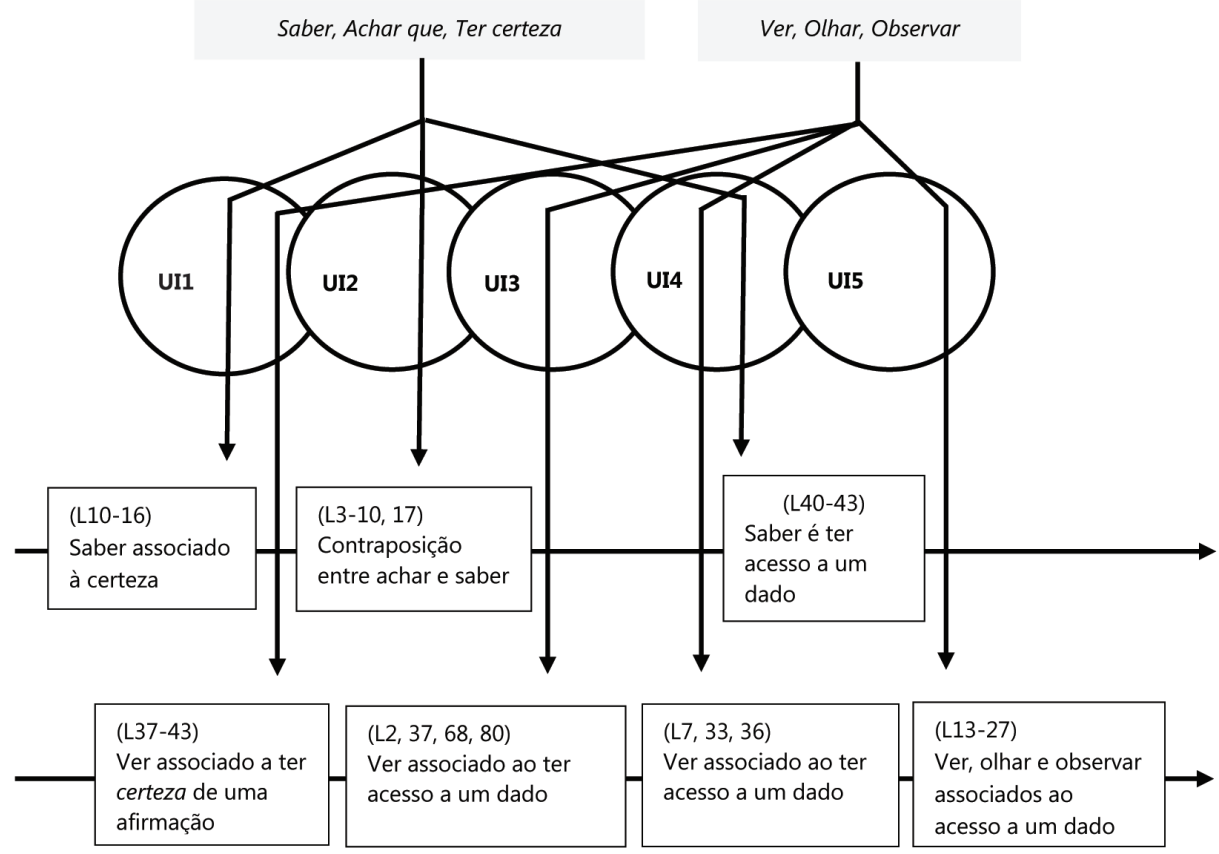

Figura 9. Representação do uso de palavras/expressões relacionadas a ações na construção da prática de uso de evidências. 
Como recursos discursivos relacionados a esses "modos de fazer" são usados pela turma para negociar um modelo compartilhado de como construir respostas para questões em aulas de ciências usando evidências?

As discussões que destacamos não se tratam apenas de "fornecer a resposta certa" para questões. As interações indicam processos de negociação sobre a construção de respostas nas aulas de ciências. Não é nossa pretensão indicar que havia um consenso entre os membros do grupo sobre como eles davam respostas nas aulas de ciências. As crianças ou a professora não foram questionadas sobre isso diretamente. Antes, nossas inferências estão baseadas em recursos discursivos que os participantes usaram/ enfatizaram nas discussões em curso.

Ao descrevermos o uso desses recursos, indicamos um movimento inicial de afastamento do grupo da construção de respostas baseadas em opiniões pessoais (achar que) para o apelo à necessidade de maior certeza das afirmações (saber, ver, ter certeza).

Ao longo do tempo, o uso desses recursos discursivos se transformou à medida que saber, olhar e ver deixaram de ser associados à certeza absoluta de uma resposta e passaram a indicar acesso aos dados capazes de auxiliar na construção de respostas (Figura 10).

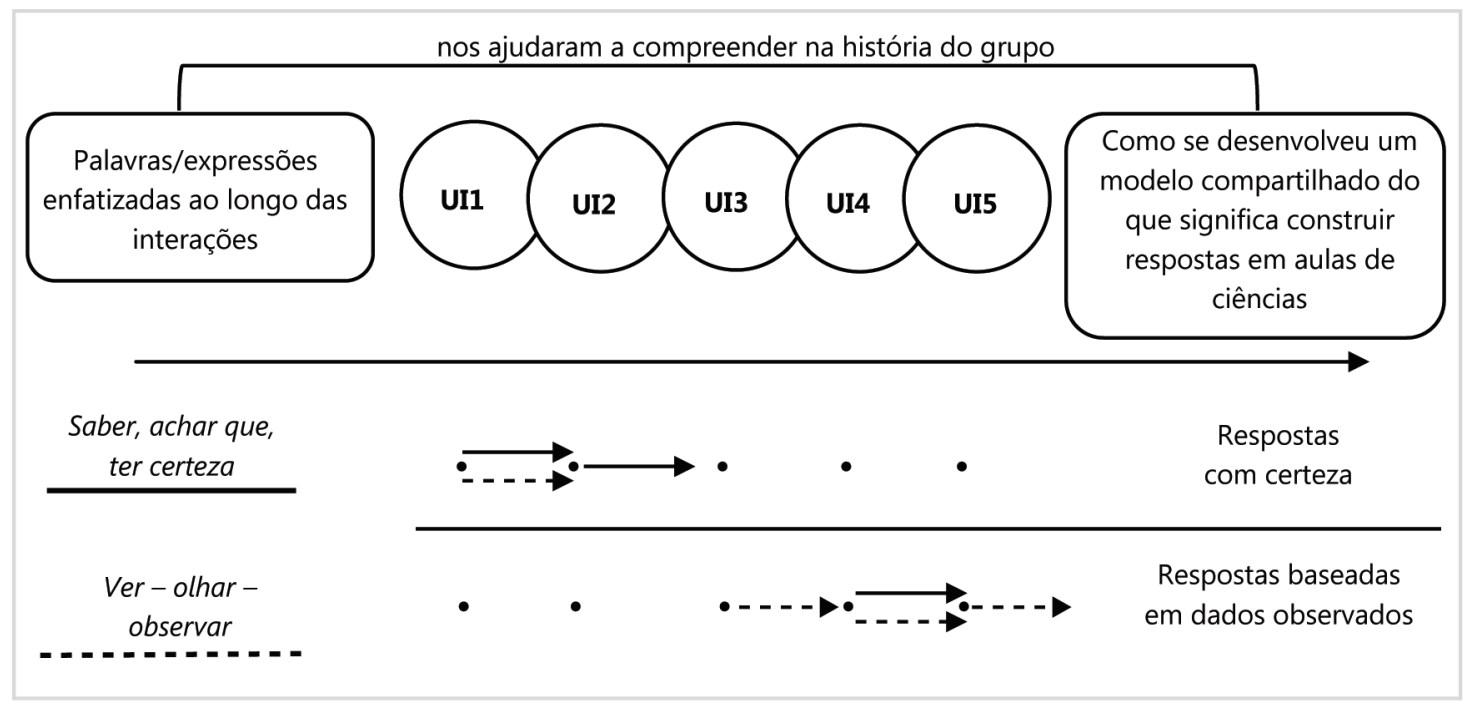

Figura 10. Representação das transformações no processo de negociação de um modelo compartilhado de construção de respostas nas aulas de ciências

\section{Discussão e Implicações do estudo}

Neste artigo, apresentamos um estudo baseado na abordagem etnográfica em educação. Identificamos, através de aspectos contextuais das interações face a face, recursos discursivos relacionados à construção da prática de uso de evidências em uma turma do $3^{\circ}$ ano do Ensino Fundamental e discutimos as negociações do grupo em torno de um modelo compartilhado de construção de respostas. 
Em nossas análises, demos maior atenção ao modo como os participantes mobilizavam recursos discursivos. Dessa forma, buscamos nos apropriar daquilo que etnógrafos em educação chamam de "talk into being", ou seja, o modo como humanos, através de recursos do discurso, compartilham, negociam e reconstroem práticas da vida cotidiana em espaços/contextos educacionais (Green \& Dixon, 1993).

Os resultados indicam características da vida cotidiana de um grupo específico em aulas de ciências. Assim, as transformações no uso de recursos discursivos que descrevemos estão situacionalmente definidas e imersas em uma série de vivências e contextos que perpassam a existência dos participantes da presente pesquisa. Dessa forma, é fundamental um diálogo com outros estudos sobre o uso de evidências entre crianças.

Um primeiro aspecto significativo nesse diálogo é o movimento de distinção entre opiniões pessoais e uso de evidências no processo de construção de respostas. Outros pesquisadores também têm investigado particularidades desse tipo de processo. Berland e McNeill (2010), por exemplo, destacam o papel do professor nesse sentido. Esses autores indicam que o professor teve um papel importante em ajudar os alunos a identificar de modo explícito os argumentos que estavam sendo usados para auxiliar na distinção entre uma opinião e uma evidência. Nos eventos relatados em nosso estudo, observamos outro modo de ação. Nos primeiros eventos de análise, a professora não se referiu de modo explícito às evidências ou argumentos, mas buscou engajar os alunos em um forma diferenciada de pensar nas respostas, algo que demandasse observação para formulação de afirmações. Referência direta às evidências surgiu apenas mais tarde.

Também encontramos alguns aspectos interessantes no estudo de Monteira e Jiménez-Aleixandre (2015) para nossa discussão. Essas autoras analisaram um grupo de crianças ao longo de um ano e as interações apresentadas possuem aproximações com nossas análises. Nas discussões, há alunos que também fazem referência ao "ver" para garantir a certeza de uma resposta e há tentativas da professora de distinguir entre o que os alunos estavam "achando/imaginando" e os testes que o grupo iria realizar. Indicamos, portanto, que esses aspectos também foram significativos nesse estudo. Nesse caso, a análise das autoras deu enfoque à relevância do papel da observação como uma prática prolongada que foi importante no processo de revisão das respostas que eram construídas pelo grupo.

Nesse sentido, entendemos que no contexto do $1^{\circ}$ ciclo do Ensino Fundamental as crianças são introduzidas a uma série de práticas escolares muito distintas de suas vivências anteriores (Neves, Gouvêa, \& Castanheira, 2011), o que também se aplica às práticas da ciência escolar que irão acompanhá-las por um longo percurso. Isso demanda uma atenção especial à introdução dessas práticas. Dessa forma, indicamos que algo relevante nesse contexto diz respeito à construção de distinções entre diferentes formas de se construir respostas. $\mathrm{O}$ uso de evidências, fundamental no modo como a ciência escolar constrói respostas, pode ser iniciado mesmo antes que o professor fale explicitamente de evidências. Ou seja, usar evidências nos Anos Iniciais também 
significa trabalhar o que é e como construir uma 'boa' resposta na ciência escolar.

Outro aspecto que chama a atenção se refere aos caminhos percorridos pelo grupo na construção de respostas. Desde a primeira unidade interacional analisada; há questões, colocadas pela professora, pela pesquisadora ou pelas crianças; que são seguidas de respostas discordantes entre si. A partir dessas discordâncias, começa a acontecer o trabalho com dados que, ao longo dos eventos, foi relacionado a um modelo compartilhado (Bloome et al., 2005) de construção de respostas usando evidências.

Sasseron e Carvalho (2014), em estudo sobre uso de evidências entre crianças, indicam outro caminho na construção de respostas. Estudando ações em aulas de ciências que contribuem para a construção de argumentos, as autoras identificaram um caminho não intuitivo: o trabalho com evidências não começava a partir da discussão em torno de uma afirmação. Nesse caso, as afirmações/respostas do grupo foram sendo construídas a partir da ocorrência de diversas situações em que as crianças analisavam os dados fornecidos pela professora. Em nosso estudo, discussões em torno da interpretação e uso de evidências também nos pareceram significativas. Porém, estas discussões ocorrem em situações em que as crianças faziam afirmações e/ou colocavam perguntas que levaram à busca e à análise de evidências.

Portanto, esses estudos combinados aos resultados da presente pesquisa nos ajudam a reconhecer uma diversidade nos modos de se construir o uso de evidências, $o$ que demanda da área de Educação em Ciências um aprofundamento sobre o que significa essa prática entre crianças e as possibilidades de sua introdução na ciência escolar.

Essa implicação está relacionada a outro aspecto relevante deste estudo: a viabilidade e importância do desenvolvimento de estudos que valorizem a argumentação enquanto processo nas aulas de ciências. Essa lacuna na área de Educação em Ciências, gerada pela visão cristalizada que construímos sobre o que é argumentar (McDonald \& Kelly, 2012), tem levado os pesquisadores a elaborar ferramentas de análise alternativas.

A proposta que apresentamos contribui de forma significativa nesse contexto de pesquisa. Ao abordarmos o uso de evidências ao longo do tempo, construímos análises que deram maior enfoque às transformações da argumentação dos estudantes e não aos produtos argumentativos alcançados. Para isso, contrastamos diferentes momentos da história da turma na disciplina ciências para dar visibilidade às continuidades e às mudanças envolvendo o que era "usar evidências" para os participantes.

Além disso, nossas inferências foram orientadas por características contextuais da fala dos participantes. Dessa forma, valorizamos outro aspecto desafiante para a pesquisa em Argumentação: o deslocamento das análises do conteúdo do discurso para sua forma (Gumperz, 1982; Hymes, 1974). Ao utilizarmos sinais como ênfase, entonação, pausas e volume da fala, demos destaque ao modo como professora e estudantes construíam a argumentação (forma) e não apenas àquilo que era dito (conteúdo).

Por fim, destacamos que esses elementos da perspectiva etnográfica podem ser associados de maneira bastante produtiva com os construtos da área de Educação em Ciências. No presente estudo, por exemplo, associamos noções muito usadas nos estudos 
sobre argumentação, como a noção de evidência baseada na proposta de Toulmin (2006), a uma análise com elementos da Etnografia Interacional e da Microetnografia. Nesse sentido, indicamos a relevância de combinar diferentes referenciais, buscando desenvolver análises mais próximas da experiência que os próprios participantes têm do que é argumentar e usar evidências em sala de aula.

\section{Agradecimentos}

Os autores agradecem aos outros membros do Grupo de Pesquisa Êmico, bem como à Dra. Vanessa Almeida Ferraz Neves e Dra. Kely Cristina Nogueira Souto pelas valiosas discussões e trabalho em conjunto. Agradecem também à CAPES e ao $\mathrm{CNPq}$ pelo apoio financeiro.

\section{Referências}

Agar, M. (1994). Language shock: Understanding the culture of conversation. New York: William Morrow and Company.

Andrews, P. (2016). Is the 'telling case' a methodological myth? International Journal of Social Research Methodology, 19(2), 1-13. doi: 10.1080/13645579.2016.1198165

Berland,L.K., \& McNeill, K. L.(2010). A learning progression for scientificargumentation: Understanding student work and designing supportive instructional contexts. Science Education, 94(5), 765-793. doi: 10.1002/sce.20402

Berland, L., \& Reiser, B. J. (2009). Making sense of argumentation and explanation. Science Education, 93(1), 26-55. doi: 10.1002/sce.20286

Berland, L., \& Reiser, B. J. (2011). Classroom Communities' Adaptations of the Practice of Scientific Argumentation. Science Education, 95(2), 191-216. doi: 10.1002/sce.20420

Bloome, D. (2012). Classroom Etnography. In M. Grenfell, D. Bloome, C. Hardy, K. Pahl, J. Powsell, \& B. V. Street. Language, Ethnography, and Education: Bridging New Literacy Studies and Bourdieu (pp. 7-26). New York: Taylor \& Francis.

Bloome, D., Carter, S. P., Christian, B. M., Madrid, S., Otto, S., Shuart-Faris, N., \& Smith, M. (2008). Discourse Analysis in Classrooms: Approaches to Language and Literacy Research. Nova York: Teachers College Press.

Bloome, D., Carter, S. P., Christian, B. M., Otto, S., \& Shuart-Faris, N. (2005). Discourse Analysis and the Study of Classroom Language and Literacy Events: A Microethnographic Perspective. Mahwah: Lawrence Erlbaum.

Bloome, D., Katz, L., Hong, H., May-Woods, P., \& Wilson, M. (2013). Methodologies in Research on Young Children and Literacy. In J. Larson, \& J. Marsh, (Orgs.), Handbook of Early Childhood Literacy (pp. 605-632). $2^{\text {nd }}$ Ed., London: SAGE Publications. 
Capecchi, M. C. V. de M. (2013). Problematização no Ensino de Ciências. In A. M. P. Carvalho (org.). Ensino de Ciências por Investigação. São Paulo: Cengage Llearning.

Carvalho, A. M. P. (2013) Ensino de Ciências por Investigação. São Paulo: Cengage Llearning.

Castanheira, M. L. (2004). Aprendizagem contextualizada: discurso e inclusão na sala de aula. Belo Horizonte: Ceale, Autêntica.

Castanheira, M. L., Crawford, T., Dixon, C., \& Green, J. (2001). Interactional Ethnography: an Approach to Studying the Social Construction of Literate Practices. Linguistics an Education, 11(4), 353-400. doi: 10.1016/S0898-5898(00)00032-2

Ferraz, A. T., \& Sasseron, L. H. Propósitos epistêmicos para a promoção da argumentação em aulas investigativas. Investigações em Ensino de Ciências, 22(1), 42-60. Recuperado de https://www.if.ufrgs.br/cref/ojs/index.php/ienci/article/view/312

Franco, L. G. S., Cappelle, V., Munford, D. \& França, E. S. (2014). Estudando o besouro rola-bosta: Uma sequência de aulas investigativas nos Anos Iniciais do Ensino Fundamental. Revista da SBEnBio, 7, 5143-5154. Recuperado de http://www.sbenbio. org.br/wordpress/wp-content/uploads/2014/11/R0135-1.pdf

Franco, L. G. S., \& Munford, D. (2016). Raising questions and trying to answer them: a study of students' use of second hand data. In J. Lavonen, K. Juuti, J. Lampiselka, A. Uitto, \& K. Hahl (eds). Eletronic Proceedings of the ESERA 2015 Conference. Science Education Research: Engaging Learners for a sustainable future (pp. 979-990). Part 7/Strand 7, Ed. M. Andrée, \& A. P. Jiménez-Aleixandre, A. P. Helsinki, Finlândia: University of Helsinki.

Green, J., \& Dixon, C. (1993). Talking knowledge into being: Discursive and social practices in classrooms. Linguistics and Education, 5(3), 231-239. Recuperado de https:// www.researchgate.net/publication/234654077_Talking_Knowledge_into_Being_ Discursive_and_Social_Practices_in_Classrooms

Green, J., Dixon, C., \& Zaharlic, A. (2005). A etnografia como uma lógica de investigação. Educação em Revista, Belo Horizonte, 42, 13-79.

Green, J., \& Wallat, C. (1981). Ethnography and language in educational settings. Norwood, NJ: Ablex.

Green, J., \& Baker, W. D. (2017). Interactional Ethnography as a Non-Linear Logicin-Use: A Guidebook for Developing a Conceptually Driven Logic-of-Inquiry. In Midwinter Conference of NCTEAR - National Council of Teachers of English Assembly for Research, San Francisco State University, SF.

Gumperz, J. J. (1982). Discourse Strategies. $1^{\text {st }}$ edition. Cambrige University Press.

Hymes, D. (1974). The foundations of sociolinguistics: Sociolinguistic ethnography. $1^{\text {st }}$ edition. Philadelphia: University of Pennsylvania Press. 
Hug, G. B., \& McNeill, K. L. (2008). Use of First-hand and Second-hand Data in Science: Does data type influence classroom conversations? International Journal of Science Education, 30(13), 1725-1751. doi: 10.1080/09500690701506945

Ibraim, S. S., \& Justi, R. (2016). Teachers' Knowledge in Argumentation: Contributions from an Explicit Teaching in an Initial Teacher Preparation Programme. International Journal of Science Education, 38(12), 1996-2025. doi 10.1080/09500693.2016.1221546

Jaber, L. Z. \& Hammer, D. (2016). Learning to Feel Like a Scientist. Science Education, 100(2), 189-220. doi: 10.1002/sce.21202

Jiménez-Aleixandre, M. P. \& Erduran, S. (2008). Argumentation in Science Education: An Overview. In M. P. Jiménez-Aleixandre, \& S. Erduran, S. Argumentation in Science Education: perspectives from classroom based research (pp. 03-25). Dordrecht: Springer.

Kelly, G. J. (2005). Discourse, description, and science education. In R. Yerrick \& W. M. Roth (eds.). Establishing Scientific Classroom Discourse Communities: Multiple Voices of Research on Teaching and Learning (pp. 79-108). Mahwah, NJ: Lawrence Erlbaum.

Kelly, G. J. (2014). Inquiry teaching and learning: Philosophical considerations. In M. R. Matthews (ed.) Handbook of Historical and Philosophical Studies in Science Education (pp. 1363-1380). Dordrecht: Springer.

Knight-Bardsley, A. M., \& McNeill, K. L. (2016). Teacher's pedagogical design capacity for scientific argumentation. Science Education, 100(4), 645-672, 2016. doi: 10.1002/ sce. 21222

Kuhn, D. (1993). Science as argument: implications for teaching and learning scientific thinking. Science Education, 77(3), 319-337. doi: 10.1002/sce.3730770306

Manz, E., \& Renga I. P. (2017). Understanding how teachers guide evidence construction conversations. Science Education, 101(4), 584-615. doi: 10.1002/sce.21282

Martins, M., Ibraim, S. de S., \& Mendonça, P. C. C. Esquemas argumentativos de Walton na análise de argumentos de professores de química em formação inicial. (2016). Ensaio Pesquisa em Educação em Ciências, 18(2), 49-71. Recuperado de http://www.scielo.br/ pdf/epec/2016nahead/1983-2117-epec-2016180203.pdf

McDonald, S. P., \& Kelly, G. J. (2012). Beyond Argumentation: Sense-Making Discourse in the Science Classroom. In M. S. Khine (ed.) Perspectives on Scientific Argumentation: Theory, Practice and Research (pp. 265-281). Dordrecht: Springer.

Mitchell, C. J. (1984). Typicality and the case study. In: Ellens, R. F. (ed.), Ethnographic research: A guide to general conduct. New York: Academic Press.

Monteira, S. F., \& Jiménez-Aleixandre, M. P. (2015). The Practice of Using Evidence in Kindergarten: The Role of Purposeful Observation. Journal of Research in Science Teaching, 52(6), 1-27. doi: 10.1002/tea.21259 
Munford, D., \& Lima, M. E. C. C. (2007). Ensinar ciências por investigação: em que estamos de acordo? Ensaio Pesquisa em Educação em Ciências, 9(1). Recuperado de http://www.portal.fae.ufmg.br/revistas/index.php/ensaio/article/view/122/172.

Munford, D., Souto, K. C. N., \& Coutinho, F. A. (2014). A etnografia de sala de aula e estudos na educação em ciências: contribuições e desafios para investigações sobre o ensino e a aprendizagem na educação básica. Investigações em Ensino de Ciências, 19(2), 263-288. Recuperado de https://www.if.ufrgs.br/cref/ojs/index.php/ienci/article/ viewFile/80/55.

Munford, D., \& Teles, A. P. S. S. (2015). Argumentação e a construção de oportunidades de aprendizagem em aulas de ciências. Ensaio Pesquisa em Educação em Ciências, 17, 161-185. Recuperado de http://www.scielo.br/pdf/epec/v17nspe/1983-2117-epec-170s-00161.pdf.

National Research Council. (2012). A Framework for $k 12$ Science Education: Practices, Crosscutting Concepts and Core Ideas. New York, National Academy Press.

Neves, V. F. A., Gouvêa, M. C. S., \& Castanheira, M. L. (2011). A passagem da educação infantil para o ensino fundamental: tensões contemporâneas. Educação e Pesquisa, São Paulo, 37(1), 121-140. Recuperado de http://www.scielo.br/scielo.php?script=sci_ arttext\&pid=S1517-97022011000100008.

Osborne, J., Erduran, S., \& Simon, S. (2004). TAPing into argumentation: developments in the application of Toulmin's argument pattern for study science discourse. Science Education, 88(6), 915-933. doi: 10.1002/sce.20012

Ryu, S., \& Sandoval, W. A. (2012). Improvements to Elementary Children's Epistemic Understanding from sustained Argumentation. Science Education, 86(3), 488-526. doi: $10.1002 /$ sce. 21006

Sandoval, W. A., \& Millwood, K. A. (2008). What can argumentation tell us about epistemology? In M. P. Jiménez-Aleixandre, \& S. Erduran (eds.). Argumentation in Science Education: Perspectives from classroom-based research (pp. 68-85). Dordrecht: Springer.

Sasseron, L. H., \& Carvalho, A. M. P. (2008). Almejando a alfabetização científica no ensino fundamental: a proposição e a procura de indicadores do processo. Investigações em Ensino de Ciências, 13(3), 333-352. Recuperado de https://www.if.ufrgs.br/cref/ojs/ index.php/ienci/article/view/445/263.

Sasseron, L., H. \& Carvalho, A. M. P. (2014). A construção de argumentos em aulas de ciências: o papel dos dados, evidências, e variáveis no estabelecimento de justificativas. Ciência \& Educação, 20(2), 393-410. Recuperado de http://www.scielo.br/pdf/ciedu/ v20n2/1516-7313-ciedu-20-02-0393.pdf. 
Scarpa, D. L., \& Trivelato, S. L. F. Movimentos entre a cultura escolar e cultura científica: análise de argumentos em diferentes contextos. Revista Internacional de Investigación en Educación, 6(12), 69-85. Recuperado de http://revistas.javeriana.edu.co/index.php/ MAGIS/article/view/7202

Spradley, J. P. (1980). Participant Observation. Harcourt Brace Jovanovich College Publishers. Orlando, Florida.

Toulmin, S. E. (2006). Os usos do argumento. $2^{\text {a }}$ ed. São Paulo: Martins Fontes.

Wolcott, H. F. (1994). Transforming qualitative data. Thousand Oaks, CA: Sage.

Yun, S. M., \& Kim, H. (2015) Changes in Students' Participation and Small Group Norms in Scientific Argumentation. Research in Science Education, 45(3), 465-484. Recuperado de https://link.springer.com/article/10.1007/s11165-014-9432-z

Zembaul-Saul, C., McNeill, K. L., \& Hershberger, K. (2013). What's your evidence? Engaging k-5 in constructing explanations in science. New York, Pearson Allyn \& Bacon.

Luiz Gustavo Franco

${ }^{(1)}$ http://orcid.org/0000-0002-1009-7788 Universidade Federal de Minas Gerais

Faculdade de Educação

Belo Horizonte, Brasil

luiz.gfs@hotmail.com

Danusa Munford

(1) http://orcid.org/0000-0001-7071-4904 Universidade Federal de Minas Gerais

Faculdade de Educação

Belo Horizonte, Brasil

danusamun@gmail.com

Submetido em 18 de Novembro 2016

Aceito em 07 de Maio 2017

Publicado em 31 de Agosto de 2017 